\title{
The use of acupuncture as a differential to control chronic pain
}

\author{
Costa, G.S1, Santos, O.C2, MeloT.R.C3, Dias, W.R.L4, Torres, R.L.N5, Silva, C.C6
}

1,2,3,4,5Academics of the Nursing Bachelor Course-Asces-Unita, 6Teacher of the Bachelor of Nursing Course-Asces-Unita

\begin{abstract}
Introduction: Acupuncture is a millenary therapeutic technique, whose practice implies the energetic balance of individuals. This therapy, usually, applies needles into acupoints, which when stimulated, promote several health benefits. With greater dissemination, Acupuncture has been an alternative means in the relief of chronic pain. Objectives: Describe the therapeutic efficacy of the use of Acupuncture in chronic pain control. Methodology: It is an integrative review, whose articles analyzed were obtained through analysis of databases: LILACS, MEDLINE and SciELO. The descriptors used were: Acupuncture, Pain, Nursing, and Traditional Chinese Medicine. Such analysis was held on September 22-24, 2017, using the following inclusion criteria: articles published in Portuguese, English and Spanish, from 2011 to 2016, and deleted all articles that do not possess the theme of the study. As a conductive question: The efficacy of the use of Acupuncture for chronic pains? Results and discussion: By means of the criteria 83 publications were identified, of which 72 were deleted by the eligibility criteria. Articles obtained have shown that the treatment is carried out at strategic points, which in some cases provide immediate analgesia and aims to improve or cure of chronic pain. Among the studies reviewed, technique as Electro Acupuncture, Auriculo Acupuncture, Craniopuncture are the most used and which allow the development of good results, aiming at a supplement and improvement of allopathic treatment, improving the prognosis of the patient. Conclusion: It seems clear, that the use of acupuncture, decreases the pain and discomforts levels, having an action similar with the chronic pain medicines.
\end{abstract}

Keywords: Acupuncture; Pain; Nursing; Traditional Chinese Medicine.

*Correspondence to Author:

Costa, G.S

Academics of the Nursing Bachelor

Course-Asces-Unita

How to cite this article:

Costa, G.S, Santos, O.C, MeloT. R.C, Dias, W.R.L, Torres, R.L.N, Silva, C.C. The use of acupuncture as a differential to control chronic pain.International Journal of Pain Research and Treatment, 2018, 1:1

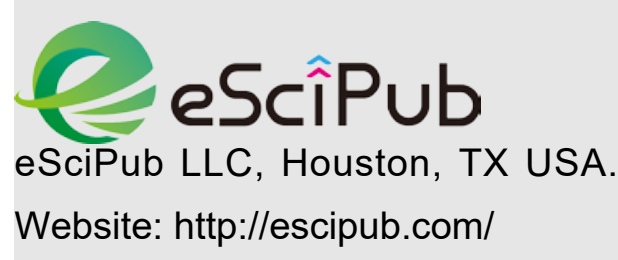

Website: http://escipub.com/ 